\title{
Pengaruh Rendaman pada Indirect Tensile Strength Campuran AC-BC dengan Limbah Plastik sebagai Agregat Pengganti
}

\author{
*Anissa Noor Tajudin", Latif Budi Suparma² \\ ${ }^{1}$ Jurusan Teknik Sipil, Universitas Tarumanagara, Jakarta, \\ ${ }^{2}$ Universitas Gadjah Mada, Sleman \\ *) anissat@ft.untar.ac.id
}

Received: 2 Oktober 2017 Revised: 28 November 2017 Accepted: 6 Desember 2017

\begin{abstract}
The pavement vulnerability of moisture and the risk of environment quality depression caused by plastic waste became the main reason of the effort to increase pavement strength with the use of plastic waste. This study was conducted to understand moisture effect to the fatigue risk with Indirect Tensile Strength (ITS) of AC-BC Hotmix with the use of plastic waste as aggregate substitution. The variance of plastic waste used are 0\%, 25\%, and 50\% of aggregate volume passing sieve No. 4 and retaining on sieve No. 8. The test was conducted with the immersion time of 30 minutes, 1 day, 2 days, 4 days, and 7 days. The result of ITS test showed that longer immersion time will make Tensile Strength Ratio (TSR) become lower. TSR values of 0\% plastic waste at the immersion time of 30 minutes, 1 day, 2 days, 4 days, and 7 days respectively are 100\%; 79,13\%; 62,18\%; 54,19\%; and 44,25\%. For $25 \%$ plastic waste are 100\%, 82,12\%, 66,68\%, 64,03\%, and 56,91\%. And for the 50\% plastic waste are $100 \%, 96,21 \%, 84,34 \%, 80,53 \%$, and $76,21 \%$.
\end{abstract}

Keywords: Plastic waste, AC-BC hotmix, indirect tensile strength

\begin{abstract}
Abstrak
Kerentanan material perkerasan terhadap air dan resiko penurunan mutu lingkungan akibat limbah plastik menjadi latar belakang upaya peningkatan kekuatan perkerasan dengan menggunakan limbah plastik. Penelitian ini dilakukan untuk mengetahui pengaruh air terhadap potensi retakan dengan melakukan pengujian kuat tarik tak langsung (Indirect Tensile Strength) campuran AC-BC dengan penggunaan biji limbah plastik HDPE sebagai agregat pengganti. Variasi biji limbah plastik yang digunakan adalah sebesar 0\%, 25\%, dan 50\% terhadap volume agregat yang lolos saringan no. 4 dan tertahan no. 8. Analisa dilakukan pada perendaman selama 30 menit, 1 hari, 2 hari, 4 hari, dan 7 hari. Hasil pengujian menunjukkan bahwa semakin panjang durasi perendaman, maka nilai Tensile Strength Ratio (TSR) atau kuat tarik campuran semakin berkurang. Nilai TSR pada perendaman selama 30 menit, 1 hari, 2 hari, 4 hari, dan 7 hari pada variasi plastik 0\%, berturut-turut sebesar 100\%; 79,13\%; 62,18\%; 54,19\%; dan 44,25\%. Untuk campuran variasi plastik 25\% sebesar 100\%, $82,12 \%, 66,68 \%, 64,03 \%$, dan 56,91\%. Sedangkan untuk campuran variasi plastik 50\% sebesar 100\%, 96,21\%, $84,34 \%, 80,53 \%$, dan $76,21 \%$.
\end{abstract}

Kata kunci: Limbah plastik, campuran $A C-B C$, indirect tensile strength

\section{Pendahuluan}

Terdapat banyak faktor yang mempengaruhi kepekaan perkerasan jalan lentur terhadap pengaruh air, antara lain sifat agregat yang peka terhadap air dan sifat kohesi-adhesi pada aspal pengikat. Curah hujan tidak menentu ditambah dengan beban lalulintas berlebih akan semakin mempercepat kerusakan 
perkerasan. Di lain sisi, limbah plastik merupakan salah satu jenis limbah yang sulit untuk terurai dengan tingkat penggunaan yang tinggi.

Peningkatan jumlah limbah plastik seharusnya diiringi dengan pengelolaan yang baik. Di DKI Jakarta, jumlah limbah plastik pada tahun 2014 adalah sebesar $14,02 \%$ atau ketiga tertinggi setelah limbah organik dan limbah kertas (BPS DKI Jakarta, 2016). Kerentanan material perkerasan terhadap air dan bertambahnya resiko penurunan mutu lingkungan akibat limbah plastik menjadi latar belakang upaya peningkatan kekuatan perkerasan dengan menggunakan material limbah plastik.

Penelitian ini dilakukan untuk mengetahui pengaruh air terhadap potensi retakan (fatigue) dan alur (rutting) dengan melakukan pengujian kuat tarik tak langsung (Indirect Tensile Strength) campuran panas AC-BC dengan penggunaan biji limbah plastik HDPE sebagai agregat pengganti. Variasi biji limbah plastik yang digunakan adalah sebesar $0 \%, 25 \%$, dan $50 \%$ terhadap volume agregat yang lolos saringan no. 4 dan tertahan no. 8. Analisa dilakukan pada perendaman selama 30 menit, 1 hari, 2 hari, 4 hari, dan 7 hari.

Asphalt Concrete - Binder Course (AC-BC) disebut juga lapis antara-aspal beton, yaitu suatu lapisan yang merupakan bagian dari lapis permukaan aspal beton yang berada di antara lapis aus (AC-WC) dan lapis pondasi (AC-Base). Spesifikasi Umum Perkerasan Jalan menetapkan gradasi kasar dan halus untuk campuran AC-BC. Sumiati dan Sukarman (2014) menyatakan bahwa agregat bergdradasi kasar dapat digunakan pada daerah yang mengalami deformasi tinggi seperti pada gerbang tol, daerah pegunungan, dan pada daerah dekat lampu merah.

Sebagian besar bahan penyusun aspal beton adalah agregat. Agregat merupakan material yang rentan terkena kerusakan oleh air karena sifatnya yang hydrophobic, sehingga dalam perencanaan dibutuhkan perhitungan yang matang agar lapisan dapat secara efektif berfungsi sesuai dengan umur rencana dan indeks pelayanan akhir yang diharapkan. Menurut Sengoz dan Agar (2007), kerusakan akibat air pada lapis aspal beton dapat disebabkan karena beberapa factor, yaitu: (1) jenis agregat, baik agregat kasar dan halus harus diuji ketahanannya terhadap air. Agregat yang sensitif terhadap air akan rentan mengalami stripping. (2) Sumber minyak dan proses distilasinya sampai menjadi aspal. (3) Properti campuran aspal beton. Kadar rongga udara dan permeabilitas campuran yang dipengaruhi oleh proses pemadatan, gradasi agregat dan kadar aspal menjadi salah satu faktor paling penting karena properti tersebut menentukan tingkat kejenuhan dan pengaliran air. (4) Ketebalan lapis aspal juga berpengaruh pada kerentanan campuran terhadap air karena akan menentuka durabilitas campuran. (5) Kondisi lingkungan dan volume lalu-lintas akan mempengaruhi tingkat stripping. Kerusakan akibat air lebih sering terjadi pada daerah dengan curah hujan dan salju tinggi. Volume lalu-lintas dan muatan sumbu tinggi akan meningkatkan potensi stripping.

Polyethylene $(\mathrm{PE}) \mathrm{C}_{\mathrm{n}} \mathrm{H}_{2 \mathrm{n}}$ merupakan salah satu jenis plastik yang paling luas penggunaannya dalam berbagai sektor, seperti kemasan makanan, tekstil, peralatan lab, dan automotif. PE memiliki densitas antara 0,91 sampai $0,97 \mathrm{~g} / \mathrm{cm}^{3}$. PE berdensitas rendah biasa disebut low density polyethylene dan $\mathrm{PE}$ berdensitas tinggi biasa disebut dengan high density polyethylene (Arutchelvi et al., 2007; Baker dan Mead, 2002).

HDPE merupakan jenis polietilen yang memiliki tingkat kerapatan tinggi, sehingga bahan ini tahan terhadap panas, dingin, air, cuaca, goresan, serta bahan isolator yang baik (Schwarz, 1986). Kadhim (2017) menyebutkan bahwa penggunaan HDPE sangat populer karena kekuatan mekanisnya, harga yang murah, proses yang mudah, dan ketahanan kimiawi dan biologis yang baik.

HDPE sebagai salah satu jenis plastik yang memiliki ketahanan terhadap suhu tinggi, tumbukan, dan air seharusnya sesuai jika diaplikasikan pada campuran beraspal panas, baik sebagai modifikasi aspal, agregat pengganti, atau pelapis agregat.

Awwad dan Shbeeb (2007) melakukan penelitian mengenai perbaikan karakteristik aspal yang dicampur dengan polyethylene (PE) untuk menentukan jenis PE dan prosporsi terbaik untuk pencampuran dengan aspal. Hasil penelitian tersebut menunjukkan bahwa modifikasi aspal dengan HDPE yang dicacah menghasilkan properti yang lebih baik dibandingkan dengan LDPE. Proporsi yang direkomendasikan adalah sebanyak $12 \%$ dari berat aspal yang digunakan. Penelitian tersebut juga menerangkan bahwa campuran mengalami peningkatan nilai stabilitas dan penurunan densitas (menjadi lebih ringan). Penelitian tersebut juga menunjukkan bahwa campuran yang telah dimodifikasi memiliki persentase VMA yang lebih tinggi dibandingkan dengan campuran nondimodifikasi. 
Rajasekaran dkk (2013) melakukan penelitian dengan menggunakan plastik dalam campuran aspal panas. Metode yang dilakukan adalah dry process, yaitu proses pelapisan agregat panas oleh lelehan plastik. Hasil penelitian menunjukkan bahwa agregat yang dilapisi oleh plastik tidak hanya meningkatkan kualitas campuran namun juga meningkatkan kualitas agregat itu sendiri.

Tajudin (2013) dalam penelitiannya menggunakan plastik HDPE sebagai agregat pengganti pada campuran AC-BC. Hasil penelitian menunjukkan bahwa biji limbah plastik HDPE dapat digunakan sebagai agregat kasar pengganti untuk agregat gradasi lolos saringan no. 4 dan tertahan saringan no. 8 karena nilai volumetrik, Marshall, dan IRS memenuhi spesifikasi yang disyaratkan pada semua variasi kadar plastik yang diuji yaitu $0 \%, 25 \%$, dan 50\%. Tajudin dan Suparma (2017) menyebutkan bahwa penggunaan plastik dalam campuran aspal beton dapat meningkatkan nilai stabilitas perendaman bahkan ketika perendaman dilakukan selama 7 hari, sehingga durabilitas campuran dengan penggunaan plastik lebih baik dibandingkan tanpa penggunaan plastik.

Menurut Xiao et al (2007), kerusakan alur (rutting) pada campuran aspal panas dapat disebabkan karena dua respon mekanik, yaitu kelelehan atau flow dan deformasi plastis. Deformasi plastis terjadi karena pergerakan agregat satu sama lain diikuti dengan kelelehan aspal. Penelitian terdahulu pernah dilakukan untuk menyederhanakan metode dalam menentukan kohesi campuran dan gesekan internal dengan melakukan uji kuat tarik tak langsung (indirect tensile strength) dan kuat tekan bebas (unconfined compressed).

Menurut British Standard Institution (1993), Indirect tensile strength (ITS) adalah kemampuan lapis perkerasan menahan kuat tarik yang disebabkan oleh beban kendaraan. Prediksi yang akurat terhadap respon dan performa perkerasan membutuhkan model teoritis yang mewakili kondisi struktur perkerasan dan masing-masing material dalam campurannya. Dalam perancangan campuran dengan metode Marshall dan Hveem, tidak ada pengujian kekuatan yang final. Banyak dari penggiat industri aspal yang meyakini bahwa uji sederhana terkait performa perkerasan perlu dilakukan, termasuk pengukuran dan penentuan properti berdasarkan kinerja perkerasan. Pengujian ITS telah berhasil digunakan untuk mengetahui kegagalan tarik, tekan, dan retak pada campuran aspal (Roque dan Buttlar, 1992).
Menurut Sunarjono (2012), pengujian ITS dapat digunakan untuk mengetahui potensi retakan (fatigue) pada campuran aspal. Retak yang disebabkan oleh repetisi beban menyebabkan adanya gaya tarik pada campuran aspal. Berbeda dengan beban tekan yang secara empiris dapat diperoleh dengan pengujian Marshall secara langsung. Besarnya beban tarik tidak dapat dilakukan pengujian secara langsung dengan Marshall, namun metode yang paling sesuai untuk mengetahui gaya tarik dari campuran aspal adalah dengan menggunakan metode Indirect Tensile Strength Test di laboratorium.

Christensen dan Bonaquist (2002) menyimpulkan bahwa pengujian ITS merupakan pengujian yang sederhana, membutuhkan beban yang rendah, dan dapat digunakan untuk menguji sampel yang tipis dan hasil core drill dari perkerasan. Pengujian ITS lebih cocok digunakan untuk keperluan berkala dalam evaluasi ketahanan terhadap alur pada campuran asphalt concrete. Pengujian yang sederhana ini memungkinkan penelitian-penelitian terkait dapat selesai dalam waktu yang relatif cepat dan tanpa pengeluaran yang besar.

ITS dilakukan pada benda uji yang berbentuk silinder. Pembebanan ini sejajar dengan diameter vertikal dari benda uji sampai titik batas kerusakan yang diindikasikan dengan terjadinya retak pada arah vertikal benda uji. Hasil keretakan benda uji, terbelah umumnya terjadi sepanjang bidang diameter. Kerusakan ini menandai beban maksimum yang dapat ditahan campuran yang mengindikasikan kuat tarik dari campuran.

Dari pembebanan maksimum yang menyebabkan benda uji mengalami failure, dapat diperoleh nilai ITS dengan menggunakan Persamaan 1 dan pembebanan diilustrasikan dalam Gambar 1.

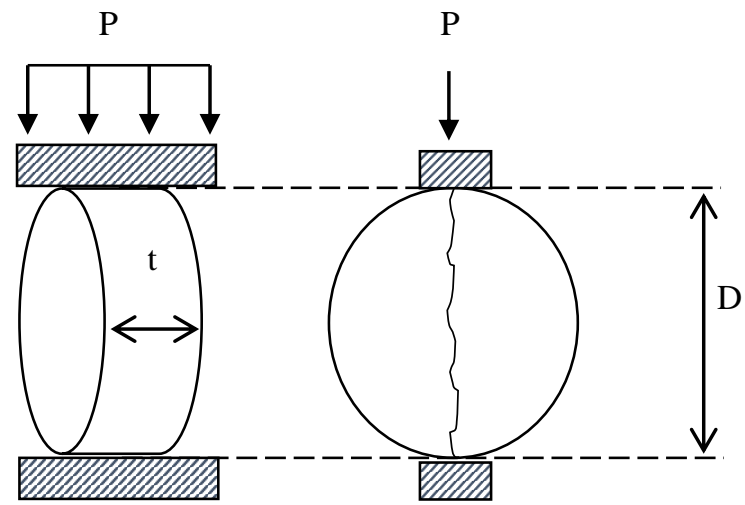

Gambar 1. llustrasi pembenanan pada ITS 
$I T S=\frac{2 \times \text { Pmaks }}{\pi \times t \times d}$

Dengan ITS adalah kekuatan tarik tidak langsung $\left(\mathrm{kg} / \mathrm{cm}^{2}\right)$, Pmaks adalah beban maksimum yang diterapkan $(\mathrm{kg}), \mathrm{t}$ adalah tinggi rata-rata benda uji $(\mathrm{cm}), \mathrm{d}$ adalah diameter benda uji $(\mathrm{cm})$.

Nilai ITS pada masing-masing perendaman kemudian digunakan untuk mengetahui Tensile Strength Ratio (TSR) atau indeks kuat tarik tidak langsung yang dihasilkan dari variasi perendaman.
Nilai TSR didapat melalui Persamaan 2. Asphalt Institute mensyaratkan nilai TSR harus lebih besar dari $80 \%$.

$T S R=\frac{I T S o}{I T S n} x 100$

Dengan TSR adalah indeks kuat tarik tidak langsung, ITSo adalah kekuatan tarik tidak langsung awal $\left(\mathrm{kg} / \mathrm{cm}^{2}\right)$, ITSn adalah kekuatan tarik tidak langsung dengan durasi perendaman $\mathrm{n}\left(\mathrm{kg} / \mathrm{cm}^{2}\right)$.

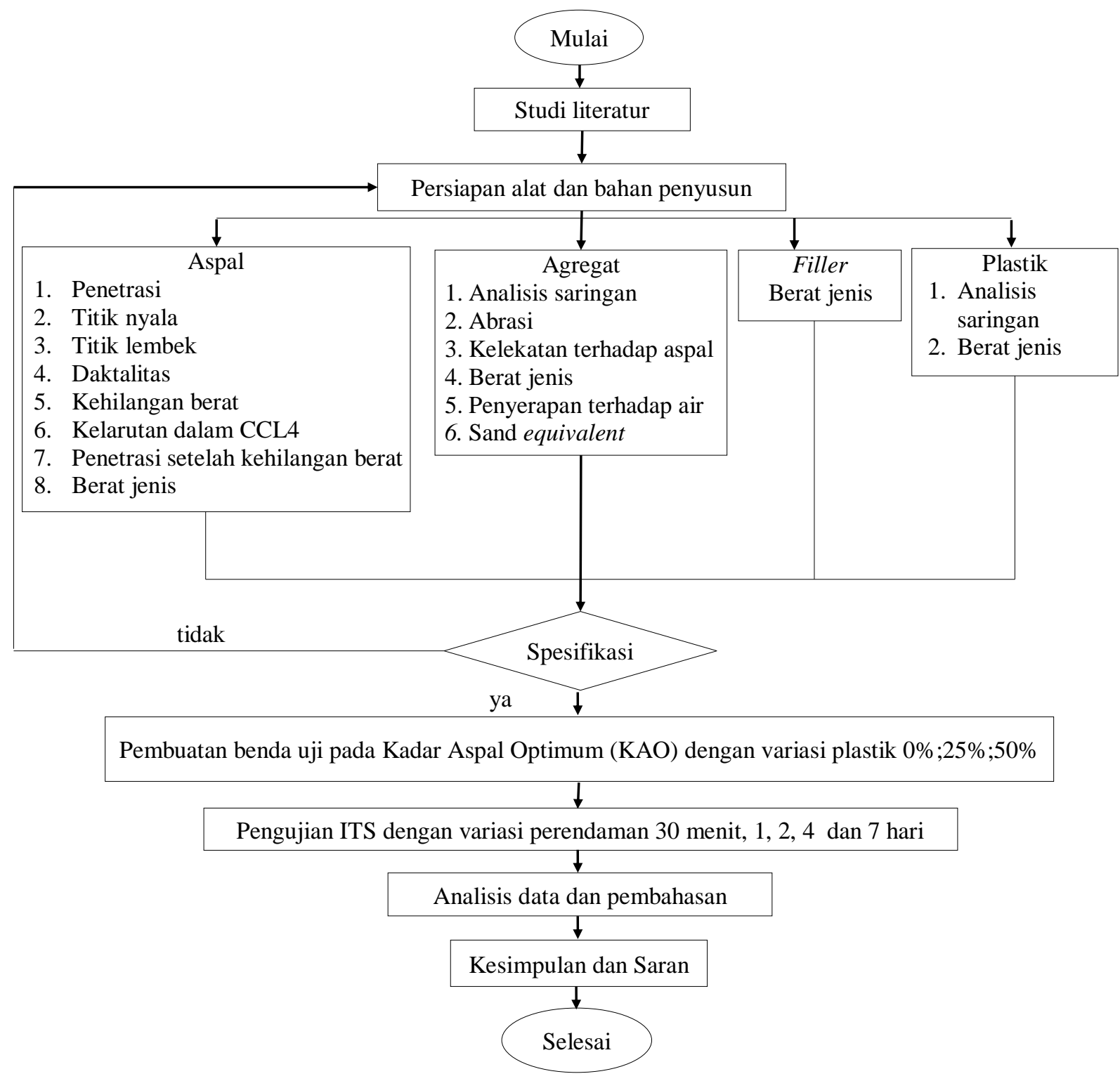

Gambar 2. Bagan alir penelitian 


\section{Metode}

Penelitian ini menggunakan metode eksperimen, yaitu metode yang dilakukan dengan mengadakan kegiatan percobaan untuk mendapatkan data. Untuk beberapa hal seperti kadar aspal optimum, digunakan data yang telah didapatkan pada penelitian sebelumnya, sehingga tahapan dan pembahasan mengenai kadar aspal optimum tidak dibahas lagi. Bagan alir penelitian disajikan pada Gambar 2 dengan langkah penelitian sebagai berikut:

Tahap I : Studi literatur dan persiapan bahan

Tahap II : Pengujian bahan

Tahap III : Perancangan benda uji

Tahap IV : Pembuatan benda uji dengan KAO

Tahap V : Perendaman dan pengujian ITS

Tahap VI : Pembahasan hasil pengujian, kesimpulan, dan saran

Dalam penelitian ini digunakan 3 variasi plastik, yaitu $0 \%, 25 \%$, dan $50 \%$ terhadap volume yang seharusnya ditempati agregat lolos saringan no. 4 dan tertahan saringan no. 8. Jika diilustrasikan dalam berat satu benda uji (1100 gram), maka proporsi berat setiap komponen agregat dalam campuran disajikan pada Gambar 3.

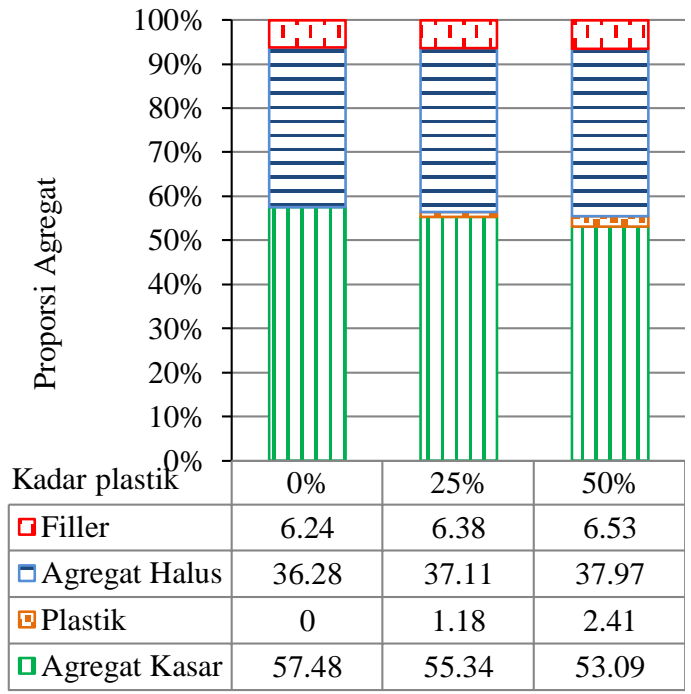

\section{Gambar 3. Proporsi berat setiap komponen agregat dalam campuran}

KAO untuk variasi kadar plastik 0\%, 25\%, dan 50\% yang digunakan secara berturut-turut adalah $6 \%$, $6,3 \%$, dan $7,1 \%$.

Hasil dari pengujian ini adalah kekuatan tarik dari benda uji dan rasio kuat tarik benda uji sebelum kondisi dengan yang telah dikondisikan (dengan variasi lama perendaman 1 hari, 2 hari, 4 hari, dan 7 hari). Tahap-tahap pengujian ITS dilakukan sesuai SNI 6753:2008 adalah (a) Benda uji yang telah diberi tanda setelah proses pemadatan didiamkan selama \pm 24 jam, kemudian dibersihkan dari kotoran yang menempel, (b) benda uji diukur tingginya dan ditimbang dalam keadaan kering untuk mengetahui berat keringnya, (c) benda uji direndam selama \pm 10 menit agar menjadi jenuh, (d) untuk mendapatkan volume isi dari benda uji, benda uji harus ditimbang didalam air lalu dikeluarkan dan keringkan permukaannya dengan lap kemudian ditimbang dalam keadaan jenuh permukaan (SSD), (e) benda uji kemudian didiamkan \pm 24 jam. (f) untuk benda uji unconditioned, benda uji terlebih dahulu didiamkan pada suhu $25^{\circ} \mathrm{C}$ selama \pm 30 menit, sedangkan untuk benda uji conditioned benda uji terlebih dahulu divacum kemudian direndam dalam waterbath dengan suhu $(60 \pm 1)^{\circ} \mathrm{C}$ selama 1 hari, 2 hari, 4 hari, 7 hari dan 14 hari. Setelah direndam benda uji kemudian didiamkan dalam suhu ruang $25^{\circ} \mathrm{C}$ selama \pm 24 jam, $(\mathrm{g})$ benda uji yang telah melalui proses persiapan kemudian diletakkan diantara plat beban uji dengan posisi ditengah, (h) mesin penguji dinyalakan, lalu dicatat angka yang ditunjukkan arloji pada pembebanan maksimum.

\section{Hasil dan Pembahasan}

\section{Hasil pengujian bahan}

Pengujian material yang akan digunakan meliputi pemeriksaan terhadap karakteristik fisik agregat, aspal, dan biji limbah plastik merupakan langkah awal untuk mengetahui apakah jenis agregat, aspal, dan biji limbah plastik yang digunakan berkualitas baik atau tidak (memenuhi batasan spesifikasi atau tidak). Penelitian ini dilakukan dengan pengujian pengujian yang sesuai dengan pedoman - pedoman pengujian yang ada dan juga didukung dengan peralatan yang sudah dikalibrasi. Agregat kasar dan agregat halus yang digunakan dalam penelitian ini berasal dari Clereng, Yogyakarta, filler yang digunakan merupakan abu batu, aspal yang digunakan adalah aspal Pertamina Pen 60/70, dan biji limbah plastik yang digunakan berasal dari PT. Inti Indah Plasindo, Solo. Hasil pemeriksaan fisik bahan penyusun campuran ditampilkan pada Tabel 1. Sesuai dengan hasil dari pengujian yang dilakukan untuk bahan aspal sudah memenuhi persyaratan dan dapat digunakan sebagai bahan campuran aspal pada AC-BC. 
Tabel 1. Hasil pemeriksaan fisik bahan penyusun campuran

\begin{tabular}{|c|c|c|c|c|c|}
\hline No. & Jenis pengujian & Syarat & Hasil & Satuan & Keterangan \\
\hline \multicolumn{6}{|c|}{ A. Agregat kasar } \\
\hline 1 & Abrasi dengan mesin los angeles & Maks 40 & 21,02 & $\%$ & Memenuhi \\
\hline 2 & Kelekatan terhadap aspal & Min 95 & 98 & $\%$ & Memenuhi \\
\hline 3 & Berat jenis semu & Min 2,5 & 2,735 & $\mathrm{~g} / \mathrm{cm}^{3}$ & Memenuhi \\
\hline 4 & Absorpsi & Maks 3 & 1,76 & $\%$ & Memenuhi \\
\hline \multicolumn{6}{|c|}{ B. Agregat halus } \\
\hline 1 & Absorpsi & Maks 3 & 1,15 & $\%$ & Memenuhi \\
\hline 2 & Sand equivalent & Min 60 & 80 & $\%$ & Memenuhi \\
\hline 3 & Berat jenis semu & Min 2,5 & 2,763 & $\mathrm{~g} / \mathrm{cm}^{3}$ & Memenuhi \\
\hline \multicolumn{6}{|c|}{ C. Filler } \\
\hline 1 & Berat jenis semu & Min 2,5 & 2,747 & $\mathrm{~g} / \mathrm{cm}^{3}$ & Memenuhi \\
\hline \multicolumn{6}{|c|}{ D. Aspal } \\
\hline 1 & Penetrasi pada $25^{\circ} \mathrm{C}$ & $60-70$ & 67,6 & $\mathrm{dmm}$ & Memenuhi \\
\hline 2 & Viskositas $135^{\circ} \mathrm{C}$ & 385 & - & $\mathrm{cSt}$ & Memenuhi \\
\hline 3 & Titik lembek & $\geq 48$ & 48,5 & ${ }^{\circ} \mathrm{C}$ & Memenuhi \\
\hline 4 & Indeks penetrasi & $\geq-1$ & $\geq-1$ & - & Memenuhi \\
\hline 5 & Daktilitas pada $25^{\circ} \mathrm{C}$ & $\geq 100$ & $\geq 100$ & $\mathrm{~cm}$ & Memenuhi \\
\hline 6 & Titik nyala & $\geq 232$ & 346 & ${ }^{\circ} \mathrm{C}$ & Memenuhi \\
\hline 7 & Kelarutan dalam Toluene & $\geq 99$ & 99,35 & $\%$ & Memenuhi \\
\hline 8 & Berat jenis & $\geq 1,0$ & 1,03 & $\mathrm{~g} / \mathrm{cm}^{3}$ & Memenuhi \\
\hline \multicolumn{6}{|c|}{ E. Biji limbah plastik } \\
\hline 1 & Berat jenis & - & 0,889 & $\mathrm{~g} / \mathrm{cm}^{3}$ & Memenuhi \\
\hline
\end{tabular}

Tabel 2. Hasil pengujian ITS dan nilai TSR

\begin{tabular}{ccccccc}
\hline \multirow{2}{*}{$\begin{array}{c}\text { Lama } \\
\text { perendaman } \\
\text { (hari) }\end{array}$} & \multicolumn{2}{c}{ Plastik 0\% } & \multicolumn{2}{c}{ Plastik 25\% } & \multicolumn{2}{c}{ Plastik 50\% } \\
\cline { 2 - 7 } & ITS & TSR & ITS & TSR & ITS & TSR \\
\hline 0 & $\mathbf{k P a})$ & $\mathbf{( \% )}$ & $\mathbf{( k P a )}$ & $\mathbf{( \% )}$ & $\mathbf{( k P a )}$ & $(\mathbf{\%})$ \\
1 & 1209 & 100,00 & 1188 & 100,00 & 1044 & 100,00 \\
2 & 957 & 79,13 & 975 & 82,12 & 1005 & 96,21 \\
4 & 752 & 62,18 & 792 & 66,68 & 881 & 84,34 \\
7 & 655 & 54,19 & 761 & 64,03 & 841 & 80,53 \\
& 535 & 44,25 & 676 & 56,91 & 796 & 76,21 \\
\hline
\end{tabular}

\section{Hasil pengujian ITS}

Nilai ITS dan TSR yang diperoleh dari penelitian ini terdapat pada Tabel 2 .

\section{Hubungan antara lama perendaman dengan nilai ITS}

Pengujian kuat tarik dilakukan dengan variasi lama perendaman 0 (unconditioned), 1, 2, 4, dan 7 hari,. Grafik pengaruh lama perendaman terhadap nilai ITS ditunjukkan pada Gambar 4.

Kekuatan campuran aspal beton sangat dipengaruhi oleh stabilitas yang berhubungan dengan kekuatan ikatan atau penguncian antara agregat dan juga kekuatan lekatan antara agregat dan aspal. Pada Gambar 4 dapat dilihat bahwa pada semua variasi plastik, semakin lama dilakukan perendaman maka nilai ITS akan semakin menurun. Hal ini diakibatkan air menyebabkan turunnya sifat adhesi atau kerekatan antara aspal dengan agregat. Menurunnya kerekatan yang diakibatkan oleh air ini akan mengurangi kohesivitas dari campuran, sehingga kekuatan campuran akan berkurang seiring dengan bertambahnya durasi perendaman.

Hasil pengujian ITS dapat menggambarkan perkiraan potensi stripping atau terlepasnya butiran-butiran agregat dari campuran. Hasil penelitian menunjukkan bahwa nilai ITS pada campuran dengan menggunakan plastik relatif lebih tinggi dibandingkan dengan tidak digunakannya plastik. Hal ini terjadi karena plastik dengan sifat plastisnya pada saat dipadatkan akan merekatkan agregat, sehingga ikatan antar agregat lebih baik dan air 
menjadi semakin susah memasuki rongga-rongga di dalam campuran. Hal ini akan menyebabkan kelekatannya dan kekuatan tariknya menjadi tinggi.

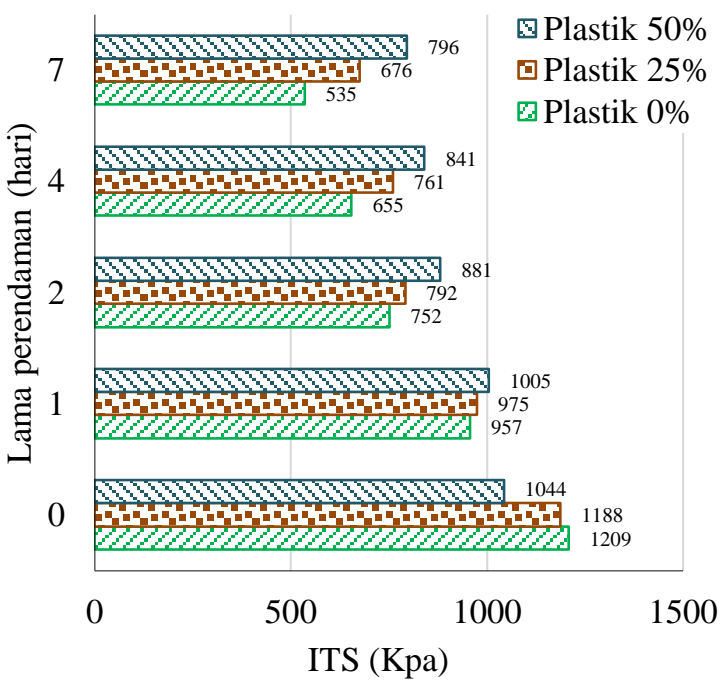

Gambar 4. Hubungan antara lama perendaman dengan nilai ITS

\section{Hubungan antara lama perendaman dengan nilai TSR}

Pengujian TSR dilakukan dengan variasi lama perendaman 0 (unconditioned), 1, 2, 4, dan 7 hari. Grafik pengaruh lama perendaman terhadap nilai TSR ditunjukkan pada Gambar 4.,. Grafik pengaruh lama perendaman terhadap nilai TSR ditunjukkan pada Gambar 5.

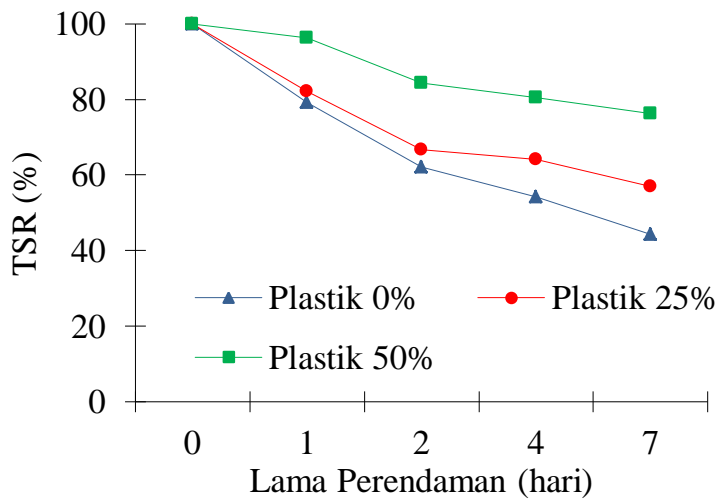

Gambar 5. Hubungan antara lama perendaman dengan nilai TSR

Nilai TSR dapat menggambarkan perkiraan kerentanan campuran terhadap air. Potensi kerusakan terhadap air diindikasikan dengan perbandingan antara nilai ITS conditioned dengan unconditioned.
Nilai TSR dalam penelitian ini pada campuran variasi plastik $0 \%$ berturut-turut sebesar $100 \%$, $79,13 \%, \quad 62,18 \%, \quad 54,19 \%$, dan $44,25 \%$. Untuk campuran variasi plastik $25 \%$ berturut-turut sebesar $100 \%, 82,12 \%, 66,68 \%, 64,03 \%$, dan $56,91 \%$. Sedangkan untuk campuran variasi plastik $50 \%$, nilai TSRnya berturut-turut sebesar 100\%, 96,21\%, $84,34 \%, 80,53 \%$, dan $76,21 \%$.

Pada Gambar 5 dapat dilihat bahwa nilai TSR akan semakin menurun seiring dengan bertambahnya durasi perendaman. Hal ini disebabkan karena pengaruh air akan menyebabkan turunnya kekuatan ikatan antar agregat dengan aspal, sehingga kuat tariknya berkurang. Dari semua benda variasi plastik, pada akhir masa rendaman tidak ada yang memenuhi persyaratan minimum nilai TSR yaitu $80 \%$. Nilai TSR yang kurang dari $80 \%$ mengindikasikan bahwa campuran rentan terhadap kerusakan yang disebabkan oleh air, sedangkan nilai TSR yang lebih dari $80 \%$ mengindikasikan bahwa campuran tahan terhadap kerusakan yang disebabkan oleh air. Durasi perendaman paling lama yang nilai TSR nya memenuhi pesrayaratan minimum adalah selama 4 hari pada campuran dengan variasi plastik 50\% yaitu sebesar $80,53 \%$.

Gambar 5 menunjukkan bahwa dari awal masa perendaman, semakin tinggi kadar plastik yang digunakan, maka nilai TSRnya semakin tinggi. Dengan kata lain,penggunaan plastik akan menghasilkan campuran dengan kuat tarik yang lebih baik dibandingkan dengan campuran tanpa penggunaan plastik. Hal ini menunjukkan bahwa penggunaan plastik akan merekatkan antar agregat sehingga campuran lebih kuat terhadap tarik pada berbagai variasi lama perendaman.

\section{Kesimpulan}

Dari hasil analisa data yang dilakukan berdasarkan pengujian dalam penelitian ini, maka dapat diambil kesimpulan bahwa air mempengaruhi kekuatan campuran beraspal panas AC-BC. Hal ini ditunjukkan dengan penurunan nilai kuat tarik campuran pada semua variasi penggunaan plastik, seiring dengan bertambahnya durasi perendaman.

Berdasarkan hasil pengujian dan analisis indirect tensile strength (ITS) dan tensile strength ratio (TSR), dapat disimpulkan bahwa kuat tarik campuranAC-BC dengan menggunakan plastik 50\% lebih baik dibandingkan dengan kuat Tarik campuran AC-BC dengan menggunakan plastik 25\% dan tanpa 
plastik. Hal ini menunjukkan campuran dengan plastik 50\% lebih tahan terhadap pengaruh rendaman dibandingkan dengan campuran yang menggunakan plastik 25\% dan campuran yang menggunakan plastik.

Tingginya kuat tarik campuran dengan variasi plastik $50 \%$ ditunjukkan dengan nilai TSR yang paling tinggi diantara variasi lainnya, yaitu sebesar $76,21 \%$ pada akhir masa perendaman selama 7 hari.

Tidak ada campuran yang memenuhi persyaratan minimum TSR $80 \%$ pada akhir masa perendaman. Durasi perendaman paling lama yang nilai TSR nya memenuhi pesrayaratan minimum adalah selama 4 hari pada campuran dengan variasi plastik $50 \%$ yaitu sebesar $80,53 \%$.

\section{Daftar Pustaka}

Arutchelvi, J., Sudhakar, M., Arkatkar, A., Doble, M., Bhaduri, S., \& Uppara, P. V. (2008). Biodegradation of polyethylene and polypropylene.. Indian J. biotechnol, 7, 9-22.

Awwad, M. T., \& Shbeeb, L. (2007). The use of polyethylene in hot asphalt mixtures. American Journal of Applied Sciences, 4(6), 390-396.

Badan Pusat Statistik Provinsi DKI Jakarta (2016). Jakarta dalam Angka 2016, BPS Provinsi DKI Jakarta, Jakarta.

Badan Standarisasi Nasional. (2008). Cara Uji Ketahanan Campuran Beraspal terhadap Kerusakan Akibat Rendaman, SNI 6753:2008, Badan Standarisasi Nasional, Jakarta.

Baker, MAM \& Mead, J. (2002). Handbook of Plastics, Elastomers, and Composites, McGraw-Hill, New York.

British Standard Institution. (1993). Method for Determination of The Indirect Tensile Strength, British Standard Institution, London.

Christensen Jr, D. W., \& Bonaquist, R. (2002). Use of strength tests for evaluating the rut resistance of asphalt concrete. Journal of the Association of Asphalt Paving Technologists, 71., 692-711.
Direktorat Jenderal Bina Marga. (2012). Spesifikasi Umum 2010-Revisi 3, Direktorat Jenderal Binamarga, Jakarta.

Kadhim, L. F. (2017). Mechanical Properties of High Density Polyethylene/Chromium Trioxide under Ultraviolet Rays. International Journal of Applied Engineering Research, 12(10), 2517-2526.

Rajasekaran, S., Vasudevan, R., \& Paulraj, S. (2013). Reuse of Waste Plastics Coated Aggregates-Bitumen Mix Composite for Road Application-Green Method.American Journal of Engineering and Research, 2, 1-13.

Roque, R., \& Buttlar, W. G. (1992). The development of a measurement and analysis system to accurately determine asphalt concrete properties using the indirect tensile mode (with discussion). Journal of the Association of Asphalt Paving Technologists, 61. 304-332.

Schwartz, WM. (1986). Ilmu Pengetahuan Populer (terjemahan) Jilid 10, Grolier International Inc, London.

Sengoz, B., \& Agar, E. (2007). Effect of asphalt film thickness on the moisture sensitivity characteristics of hot-mix asphalt. Building and environment, 42(10), 3621-3628.

Sumiati, S., \& Sukarman, S. (2014). Pengaruh Gradasi Agregat Terhadap Nilai Karakteristik Aspal Beton (AC-BC). Pilar, 10(1)., 85-91.

Samantha, R. (2012). Analisis Kekuatan Tarik Material Campuran Sma (Split Mastic Asphalt) Grading 0/11 Menggunakan Sistem Pengujian Indirect Tensile Strength(Doctoral dissertation, Universitas Muhammadiyah Surakarta).

Tajudin, AN. (2013). Pemanfaatan Limbah Plastik HDPE Sebagai Agregat Kasar Pengganti Pada Campuran Asphalt Concrete Binder Course (ACBC), Skripsi, Universitas Gadjah Mada.

Xiao, F., Amirkhanian, S., \& Juang, C. H. (2007). Rutting resistance of rubberized asphalt concrete pavements containing reclaimed asphalt pavement mixtures. Journal of Materials in Civil Engineering, 19(6), 475-483. 